\title{
Crystallization of phosphorus-doped amorphous silicon films prepared by glow discharge decomposition of silane
}

\author{
S. Squelard, K. Zellama, P. Germain \\ Groupe de Physique des Solides de l'ENS (*), Université de Paris-VII, Tour 23,
}

2, place Jussieu, 75251 Paris Cedex 05, France

and B. Bourdon

Laboratoire de Marcoussis, CR-CGE DMT, Route de Nozay, 91460 Marcoussis, France

(Reçu le 12 juin 1981, révisé le 6 août 1981, accepté le 9 septembre 1981)

\begin{abstract}
Résumé. - La cristallisation dans le silicium amorphe dopé au phosphore, et obtenu par décomposition de silane, a été observée en utilisant les mesures de conductivité électrique. Ceci nous a permis d'obtenir l'énergie d'activation $E_{\mathrm{v}}$ de la vitesse de croissance $V_{\mathrm{g}}$ en fonction de la concentration du dopage $C_{\mathrm{p}}$ (variant de 0,05 à $5 \%$ ). On trouve une énergie $E_{\mathrm{v}}$ égale à $3 \mathrm{eV}$ pour $C_{\mathrm{p}} \leqslant 0,5 \%$. Cette énergie augmente pour des concentrations de dopage supérieures. Ces résultats sont comparés avec ceux obtenus par Csepregi et al. en utilisant la méthode de canalisation. Ils obtiennent une énergie $E_{\mathrm{v}}$ indépendante du dopage et égale à $2,4 \mathrm{eV}$.

Abstract. - Crystallization kinetic of phosphorus-doped amorphous silicon films prepared by glow discharge of silane is observed by using conductivity measurements. The activation energy $E_{\mathrm{v}}$ of the growth rate $V_{\mathrm{g}}$ is deduced as a function of doping level $C_{\mathrm{p}}$ (ranging from 0.05 to $5 \%$ ). $E_{\mathrm{v}}$ has a constant value equal to $3 \mathrm{eV}$ for $C_{\mathrm{p}} \leqslant 0.5 \%$ and increases for higher values of $C_{\mathrm{p}}$. We compare these results with Csepregi et al.'s ones, obtained by channeling. They obtain $E_{\mathrm{v}}$ equal to $2.4 \mathrm{eV}$ in the whole doping level range.
\end{abstract}

1. Introduction. - Crystallization in amorphous material occurs through nucleation and the growth of the crystallites formed during the nucleation process [1]. The growth rate $V_{\mathrm{g}}$ is the rate at which the crystalline to amorphous interface moves. The nucleation rate $n$ is the number of stable crystallites which appear per unit time in an untransformed volume of unity. Experimentally $V_{\mathrm{g}}$ (as well as $n$ ) appears to be thermally activated :

$$
V_{\mathrm{g}}=V_{\mathrm{g}^{0}} \exp \left(-E_{\mathrm{v}} / K_{\mathrm{B}} T\right)
$$

$V_{\mathrm{g}^{0}}$ is independent of temperature $T, K_{\mathrm{B}}$ is the Boltzmann constant, and $E_{\mathrm{v}}$ is the activation energy of $V_{\mathrm{g}}$.

The crystallized fraction $x(t)$ is defined as $x(t)=V(t) / V_{0}$ where $V(t)$ is the total crystallized volume at time $t$, and $V_{0}$ is the total volume of the sample. The crystallized fraction $x(t)$ can be obtained from the conductivity of the layer at time $t, \sigma m(t)$,

(*) Laboratoire associé au C.N.R.S. when the conductivities $\sigma a$ and $\sigma x$ of the amorphous and crystalline materials are known through [2] :

$$
\operatorname{Ln}\left(\frac{1}{1-x(t)}\right)=\operatorname{Ln} \cdot\left[1-\frac{\left(\frac{1-\frac{\sigma m(t)}{\sigma a}}{1+2 \frac{\sigma m(t)}{\sigma a}}\right)}{\left(\frac{\frac{\sigma x}{\sigma a}-\frac{\sigma m(t)}{\sigma a}}{\frac{\sigma x}{\sigma a}+2 \frac{\sigma m(t)}{\sigma a}}\right)}\right]
$$

We have shown $[3,4]$ that $V_{\mathrm{g}}$ is generally obtained in the case of surface-induced crystallization (SIC) and $n$ is obtained from the bulk-induced crystallization (BIC), when $V_{\mathrm{g}}$ is known. In the. case of BIC, we have shown that

$$
\ln \frac{1}{1-x}
$$


varies roughly as $t^{r}$ with $1<r \leqslant 3$. We have observed that when $n=0, \ln \{1 /(1-x)\}$ varies roughly as $t^{2}$ and in the case of $n \neq 0$ it varies as $t^{3}$.

Csepregi et al. [5] compared the growth rate $\left(V_{\mathrm{g}}\right)$ obtained on undoped and doped (with electrically active impurities B, P, As) implanted a-Si films. They found that after implanting the ${ }^{31} \mathrm{P}$ impurity at concentrations ranging from 0.9 to $2.8 \times 10^{20} \mathrm{~cm}^{-3}$, the activation energy $\left(E_{\mathrm{v}}\right)$ of $V_{\mathrm{g}}$ stays constant, and the pre-exponential factor $V_{\mathrm{g}^{\mathrm{o}}}$ is multiplied by a factor of 6 . They report that for concentrations higher than $2 \times 10^{20} \mathrm{~cm}^{-3}\left(\simeq 5 \times 10^{-3}\right.$ atomic per cent), the growth rate does not appear to be strongly dependent on the dopant concentration.

Reilly and Spear [6] have studied the crystallization in undoped and doped specimens of amorphos silicon prepared by glow discharge decomposition of silane. They found a temperature of crystallization $T_{\mathrm{c}}$ equal to $620^{\circ} \mathrm{C}$ for undoped specimens. They found that phosphorus doping can reduce $T_{\mathrm{c}}$ appreciably, and observed a decrease of $110^{\circ} \mathrm{C}$ for a vapour doping level of $2.4 \times 10^{-3}$ atomic per cent. This can be associated with an increase in the growth rate and/or the nucleation rate.

The aim of this paper is to study $V_{\mathrm{g}}$ as a function of temperature and doping level, for phosphorus doped and undoped amorphous silicon films prepared by glow discharge decomposition of silane, the phosphorus doping concentration ranging from $0.5 \times 10^{-4}$ to $5 \times 10^{-2}$ (atomic concentration).

2. Experimental results. -2.1 SAMPLE PREPARATION. - Phosphorus doped and undoped amorphous silicon films have been prepared by glow discharge decomposition of silane, most of them deposited on sintered alumina substrate, some being deposited on quartz substrate. The doping is realized by addition of phosphine with silane in the gas phase during glow discharge decomposition. The phosphorus doping concentration $C_{\mathrm{p}}$ is defined as :

$$
C_{\mathrm{P}}=\frac{\left[\mathrm{PH}_{3}\right]}{\left[\mathrm{SiH}_{4}\right]}
$$

where $\left[\mathrm{PH}_{3}\right]$ is the phosphine concentration and $\left[\mathrm{SiH}_{4}\right]$ is the silane concentration. The preparation conditions detailed in [7] are summarızed in table 1 .

Thickness measurements were made with a Talystep $( \pm 0.02 \mu \mathrm{m})$. Substrates are degassed for $60 \mathrm{~min}$. at $700{ }^{\circ} \mathrm{C}$ prior to the deposition. The amorphous layers are exposed to the atmosphere between the deposition and the crystallization process.

Prior to crystallization, samples are annealed at a temperature of about $500^{\circ} \mathrm{C}$ for 15 hours in order to exodiffuse hydrogen. This will be discussed under Discussion and Conclusions.

2.2 ReSUlTS. - Electrical conductivity measurements $(\sigma)$ were made using two kinds of apparatus. The low conductivity measurements were made using a Keithley $610 \mathrm{C}$ electrometer with a relative error less than $10 \%$. In the case of high conductivity measurements, we used an AOIP Keithley Multimeter Efficace MNK 179.

We used a planar configuration contact electrode made by pressing with platinum foil. The annealing was made in an oven under argon atmosphere (stabilized at $\pm 1^{\circ} \mathrm{C}$ ). We observed no change when annealing was made in vacuum with a residual pressure of $10^{-6}$ torr.

In figures 1 to 3 we present examples of the variation of the electrical resistance $R(t)$ versus time during isothermal runs at various temperatures for samples of series 1 to 6 .

Table I. - Experimental conditions for sample deposition.

\begin{tabular}{|c|c|c|c|c|c|c|}
\hline Series & 1 & 2 & 3 & 4 & 5 & 6 \\
\hline- & - & - & - & - & - & - \\
\hline Dimensions $\left(\mathrm{mm}^{2}\right)$ & $4 \times 4$ & $4 \times 4$ & $4 \times 4$ & $4 \times 1.5$ & $4 \times 1.5$ & $4 \times 4$ \\
\hline$C_{\mathrm{P}}=\frac{\left[\mathrm{PH}_{3}\right]}{\left[\mathrm{SiH}_{4}\right]}$ & 0.05 & 0.1 & 0.5 & 1 & 5 & 0 \\
\hline $\begin{array}{l}\text { Substrate temperature of depo- } \\
\text { sition }\left({ }^{\circ} \mathrm{C}\right)\end{array}$ & 400 & 400 & 400 & 300 & 400 & 420 \\
\hline Thickness $(\mu \mathrm{m})$ & 0.5 & 0.5 & 0.5 & 0.55 & 0.6 & 0.6 \\
\hline Rate of deposition $(\AA / \mathrm{min})$. & 200 & 200 & 200 & 200 & 200 & 150 \\
\hline $\begin{array}{l}\text { Residual pressure (torr) } \\
\quad\left(\times 10^{-2}\right)\end{array}$ & 2.2 & 2 & 2 & 2 & 2.2 & 1.6 \\
\hline RF power $(W)$ & 70 & 70 & 70 & 70 & 70 & 80 \\
\hline Sample voltage (V) & +35 & +35 & +35 & +35 & +35 & 0 \\
\hline Target voltage $(\mathrm{V})$ & -500 & -500 & -500 & -500 & -500 & -450 \\
\hline Values of $\frac{R_{a}}{R_{C}}=\frac{\sigma C}{\sigma a}$ & 21 & 35 & 210 & 370 & 18 & 10 \\
\hline
\end{tabular}




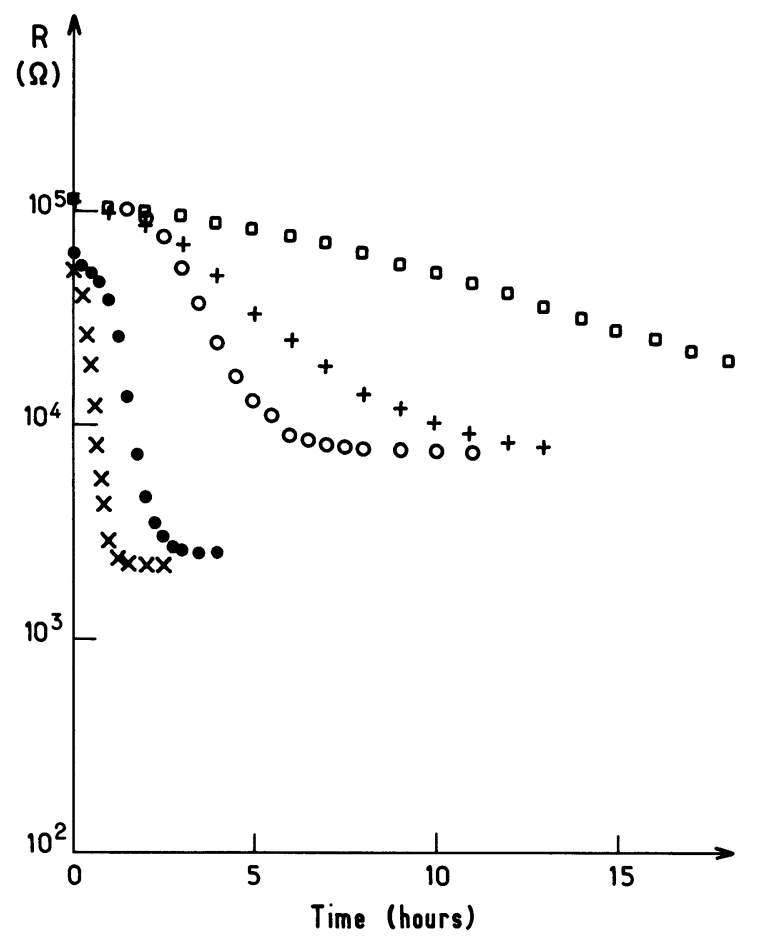

Fig. 1. - Variation of the electrical resistance versus time in phosphorus-doped $(0.05 \%)$ amorphous silicon layers for various temperatures. $\square 560^{\circ} \mathrm{C} ;+580^{\circ} \mathrm{C} ; \circ 600^{\circ} \mathrm{C} ; \bullet 620^{\circ} \mathrm{C}$; $\times 640{ }^{\circ} \mathrm{C}$

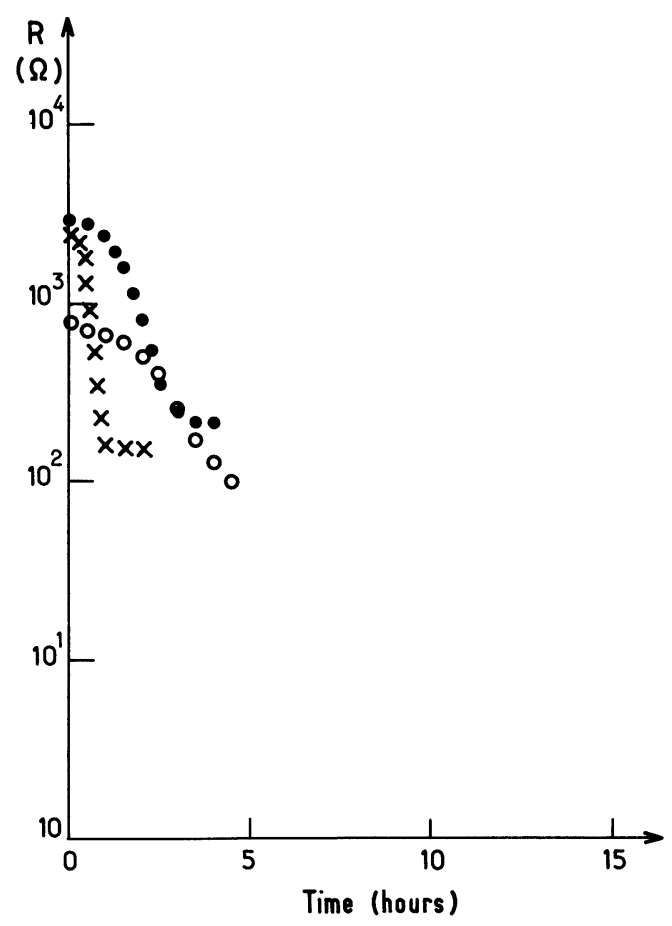

Fig. 2. - Variation of the electrical resistance versus time in phosphorus-doped $(5 \%)$ amorphous silicon layers for various temperatures. $0600^{\circ} \mathrm{C} ; \bullet 620^{\circ} \mathrm{C} ; \times 640^{\circ} \mathrm{C}$.

As observed in the case of crystallization of evaporated amorphous $\mathrm{Ge}$ and $\mathrm{Si}[3,4]$, initiation times exist, mainly for low annealing temperatures. These

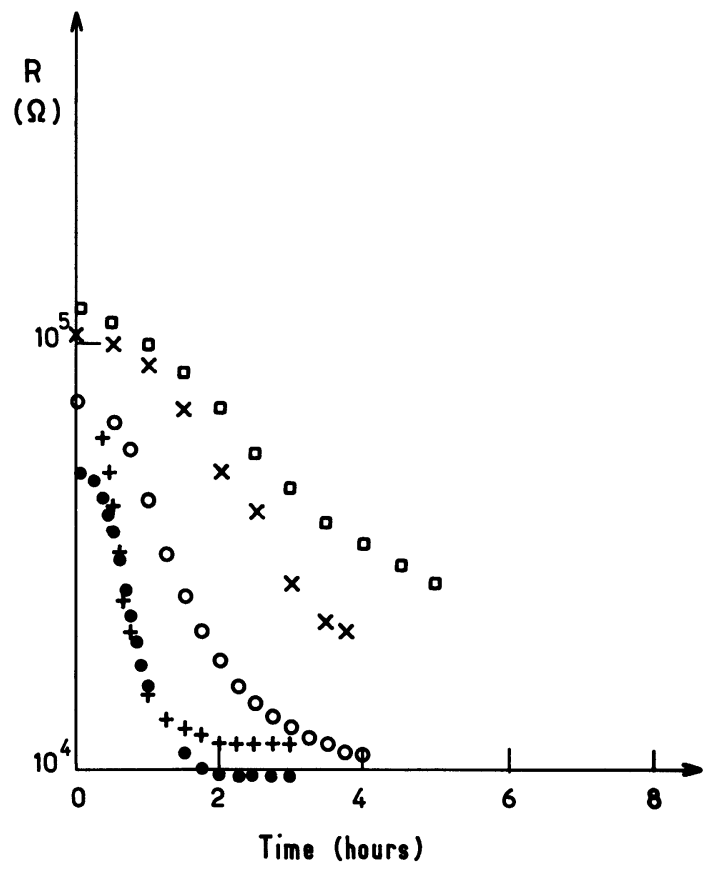

Fig. 3. - Variation of the electrical resistance versus time in undoped amorphous silicon layers for various temperatures. $\square 630^{\circ} \mathrm{C} ; \times 640^{\circ} \mathrm{C} ; 0650^{\circ} \mathrm{C} ;-660^{\circ} \mathrm{C} ;+670^{\circ} \mathrm{C}$.

initiation times are not presented in figures 1 to 3 . The lowest annealing temperature here is $560^{\circ} \mathrm{C}$, which corresponds to an initiation time $t^{\prime \prime} \simeq 12$ hours.

3. Discussion AND CONClusions. - In crystallization occurring through nucleation and growth, the observed initiation time is generally interpreted as a time during which the nucleation rate increases from zero to its steady state value [1].

In our case, it can also be due to the presence of $\mathrm{H}$ atoms inhibiting the crystallization process. But we shall show that the hydrogen effect is negligible in the present study.

In previous hydrogen exodiffusion studies on undoped [8] and heavily phosphorus doped [9] films, we showed (by nuclear reaction measurements) that a non zero residual hydrogen concentration exists, and stays constant even after crystallization. This residual concentration $C_{\text {resid }}$ is about $0.25 \%$ for undoped films and $0.16 \%$ for phosphorus doped layers. Roughly similar kinetics of $\mathbf{H}$ exodiffusion are observed for both cases.

Apart from this residual $\mathrm{H}$ concentration, it has been shown that $[8,10]$ :

(1) A weakly bound $\mathrm{H}$ whose concentration $C_{10}$ $\left(C_{10} \simeq 0.08\right.$ at. concentration) leave the sample by diffusion with a diffusion coefficient $D$ for $T<500^{\circ} \mathrm{C}$, so an annealing at $500^{\circ} \mathrm{C}$ during $t=15$ hours reduces the concentration of weakly bound $\mathrm{H}$ by a factor :

$$
\exp \left(-\frac{D \pi^{2}}{4 e^{2}} t\right) \simeq 10^{-20}
$$

with $D\left(500^{\circ} \mathrm{C}\right)=8.9 \times 10^{-13} \mathrm{~cm}^{2} / \mathrm{s}$; 
(2) A tightly bound $\mathrm{H}$, occupying isolated $\mathrm{Si}-\mathrm{H}$ bonds, whose concentration $C_{20}\left(C_{20}=0.02\right.$ at. concentrations), leave their sites for $T \geqslant 500^{\circ} \mathrm{C}$ following a first order law with a kinetic coefficient $K_{2}$. So the same annealing $\left(500^{\circ} \mathrm{C}, t=15 \mathrm{~h}\right)$ reduces the concentration of tightly bound $\mathrm{H}$ by a factor of

$$
\exp \left[-K_{2}\left(500^{\circ} \mathrm{C}\right) \times t\right] \simeq 10^{-1},
$$

with $K_{2}\left(500^{\circ} \mathrm{C}\right)=3.6 \times 10^{-6} \mathrm{~s}^{-1}$.

This implies that this above annealing removes the whole weakly bound $\mathrm{H}$ and only a part of the tightly bound $\mathrm{H}$. But we shall show that the remaining tightly bound $\mathrm{H}$ will leave the sample just at the beginning of the initiation time even at the lowest crystallization temperature $\left(560^{\circ} \mathrm{C}\right)$.

Doing the same calculation as in (2) and using $K_{2}\left(560^{\circ} \mathrm{C}\right)=1.1 \times 10^{-4} \mathrm{~s}^{-1}$, we show easily that the necessary time to decrease the tightly bound $\mathrm{H}$ concentration from $C_{20}$ to $C_{\text {resid }}$ is about $t^{\prime} \simeq 40 \mathrm{~min}$., much lower than the initiation time $\left(t^{\prime \prime} \simeq 12 \mathrm{~h}\right)$.

For each annealing temperature, the electrical resistance varies from an initial value $R(t=0)=R_{a}$, which corresponds to the amorphous phase, to a final constant value which is assumed to correspond to the crystalline phase. This will be discussed later. Thus for each isothermal run, we can calculate :

$$
\frac{R_{a}}{R_{x}}=\frac{\sigma x}{\sigma a} .
$$

The values of $\sigma x / \sigma a$ are given in table I for each series.

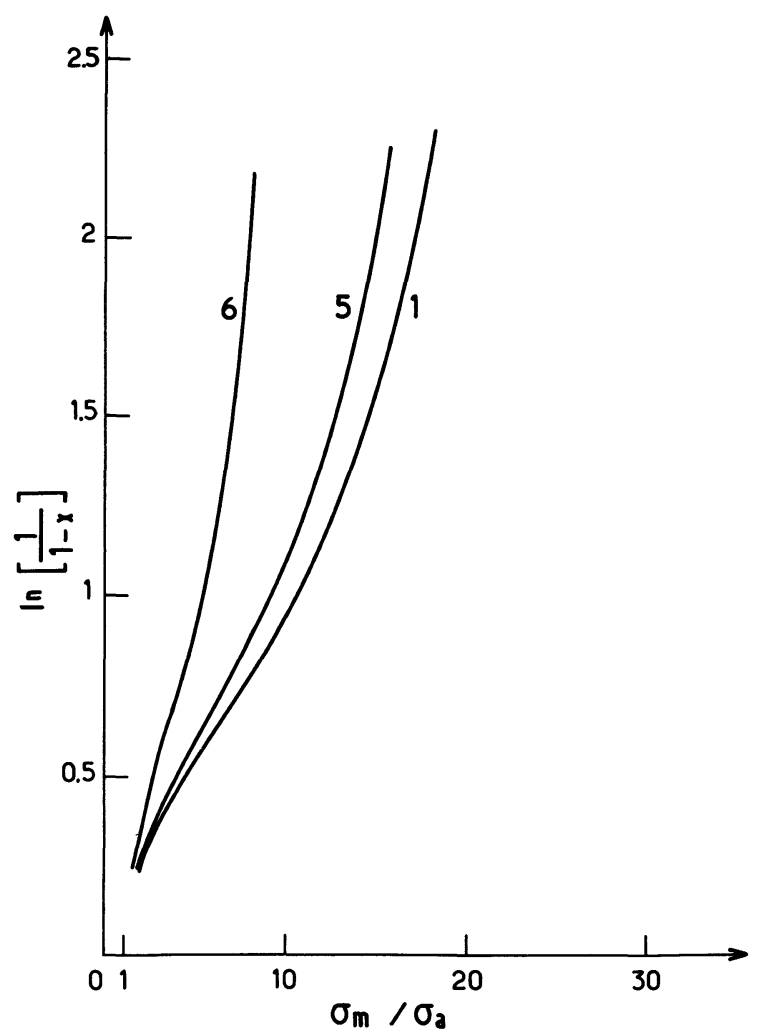

Fig. 4. - Variations of $\ln (1 / 1-x)$ versus $\sigma m / \sigma a$ for the following values of $\sigma x / \sigma a$ : curve $1, \underline{11}$; curve $5, \underline{18}$; curve $6, \underline{10}$.

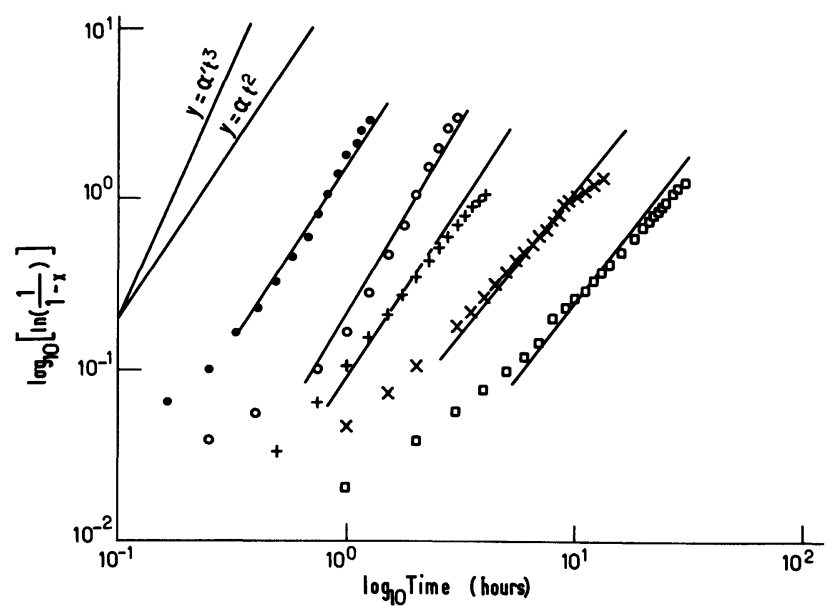

Fig. 5. - Variation of $\log _{10}[\ln (1 / 1-x)]$ versus $\log _{10} t$ for samples of series 1 annealed at various temperatures : $\square 560^{\circ} \mathrm{C}$; $\times 580^{\circ} \mathrm{C} ;+600^{\circ} \mathrm{C} ; 0620^{\circ} \mathrm{C} ; \bullet 640^{\circ} \mathrm{C}$.

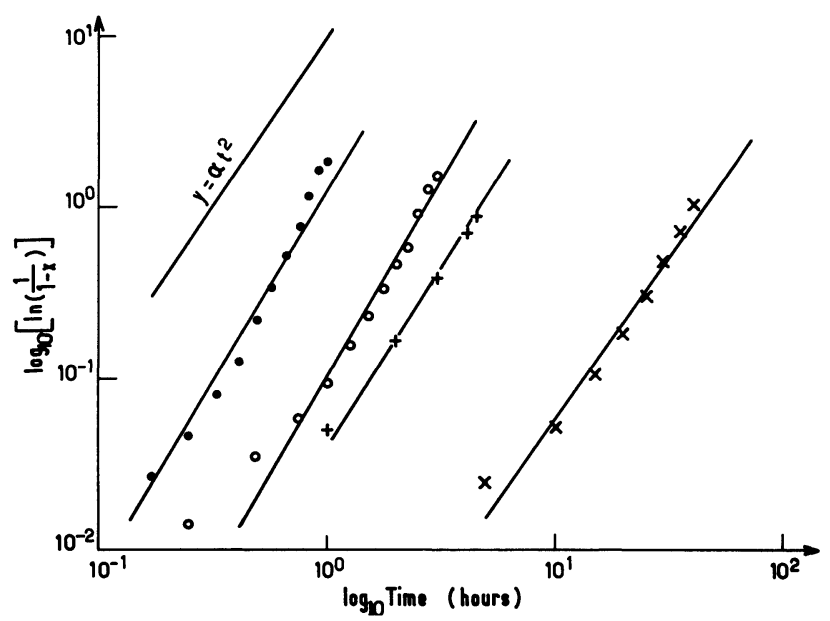

Fig. 6. - Variation of $\log _{10}[\ln (1 / 1-x)]$ versus $\log _{10} t$ for samples of series 5 annealed at various temperatures : $\times 580^{\circ} \mathrm{C}$; $+600^{\circ} \mathrm{C} ; 0620^{\circ} \mathrm{C} ; \bullet 640^{\circ} \mathrm{C}$.

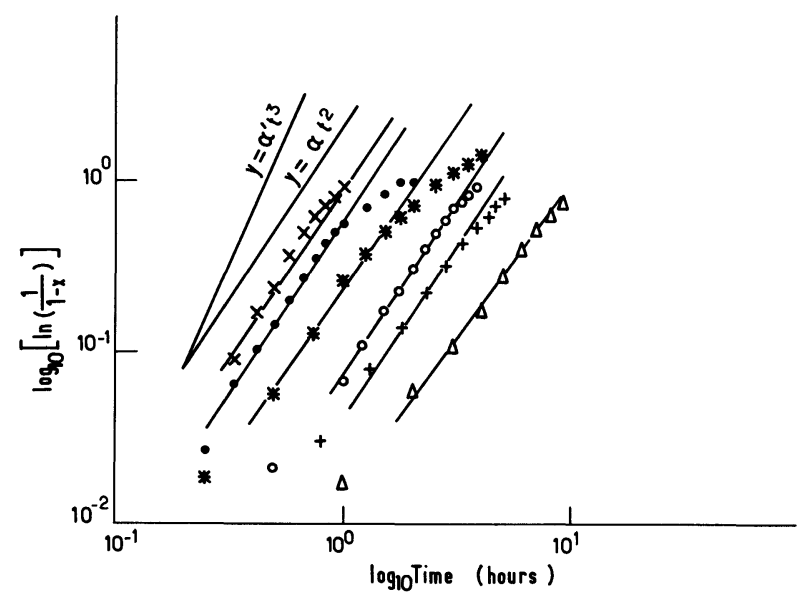

Fig. 7. - Variation of $\log _{10}[\ln (1 / 1-x)]$ versus $\log _{10} t$ for samples of series 6 annealed at various temperatures : $\triangle 620^{\circ} \mathrm{C}$; $+630^{\circ} \mathrm{C} ; 0640^{\circ} \mathrm{C} ; * 650^{\circ} \mathrm{C} ; \bullet 660{ }^{\circ} \mathrm{C} ; \times 670{ }^{\circ} \mathrm{C}$. 
Using equation (1), we obtain the variations of $\ln \{1 /(1-x)\}$ versus $\sigma m / \sigma a$ for each series (see figure 4 for example). We then deduce the variations of $\ln \{1 /(1-x)\}$ versus time. These variations are presented in figures 5 to 7 .

From these figures we observe that $\ln \{1 /(1-x)\}$ varies roughly as $t^{\alpha}$. At the beginning of the annealing time, $\alpha \simeq 1$, during a short time, then over most of the annealing time we see that $\alpha$ is much larger than 1 , smaller than 3 , and about 2 .

We have shown that such crystallization kinetics correspond to a BIC (Bulk Induced Crystallization) without homogeneous nucleation $(n=0)$ in good agreement with electron-microscopy results [3]. Therefore :

$$
\ln \frac{1}{1-x}=P \frac{\Pi}{S} \times\left(a_{0}+V_{\mathrm{g}} t\right)^{2}
$$

where $P$ is the number of crystallites present at time $t=0$ and $a_{0}$ their initial size, $S$ is the area of the sample. Barna et al. [11], using electronmicroscopy, have shown that exposure of amorphous germanium samples to the atmosphere can avoid homogeneous nucleation. As mentioned above, our samples were exposed to the atmosphere before crystallization, so we can reasonably use equation (2). In our case, figures 5 to 7 show that the predominant variation of $\ln \{1 /(1-x)\}$ is as $t^{2}$, so we can take the simplified equation :

$$
\ln \frac{1}{1-x} \simeq P \frac{\Pi}{S} V_{\mathrm{g}}^{2} t^{2}
$$

A comparison of each curve of figures 5 to 7 with equation (3) allows us to obtain a value of the quantity

$$
\sqrt{P \frac{\Pi}{S}} \times V_{\mathrm{g}}
$$

for each annealing temperature and for various doping levels. It was not possible to determine here $P / S$ but we can reasonably assume that it has a constant value for each series (i.e. for each doping level). The variation of

$$
\sqrt{P \frac{\Pi}{S}} \times V_{\mathrm{g}} \text { versus } T
$$

provides $E_{\mathrm{v}}$ for a given value of $C_{\mathrm{p}}$. We present in figure 8 the variation of $E_{\mathrm{v}}$ versus $C_{\mathrm{p}}$. For comparison we also show in this figure the variation of $E_{\mathrm{v}}$ versus $C_{\mathrm{p}}$ obtained by Csepregi et al. [5] on phosphorus-doped implanted amorphous silicon films.

The following observations may be made from an examination of figure 8 . The activation energy $E_{\mathrm{v}}$ obtained by the channelling method [5] does not depend on $C_{\mathrm{P}}$ over the entire level range investigated.
Table II. - Variations of $E_{\mathrm{v}}$ versus $C_{\mathrm{P}}$.

$\begin{array}{lllllll}C_{\mathrm{P}}(\%) & 0 & 0.05 & 0.1 & 0.5 & 1 & 5 \\ E_{\mathrm{v}}(\mathrm{eV}) & 3 & 2.6 & 3 & 3 & 3.4 & 4.3\end{array}$

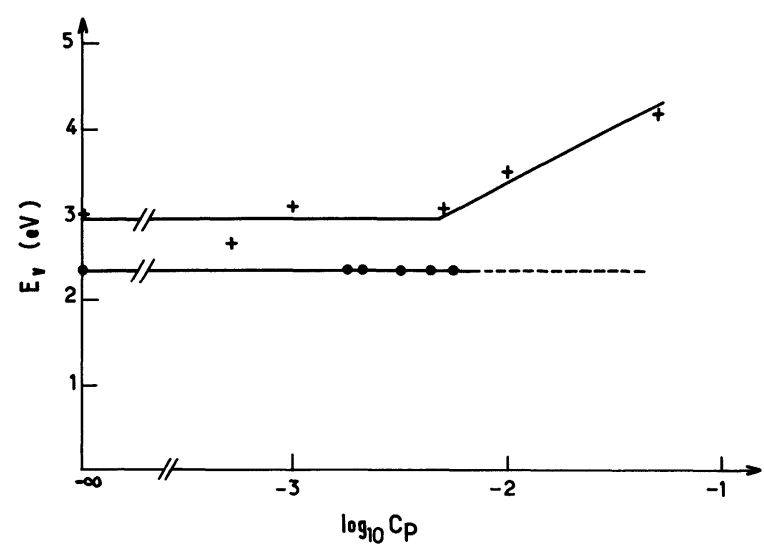

Fig. 8. - Variation of the activation energy of the growth rate $E_{\mathrm{v}}$ as a function of the phosphorus concentration $C_{\mathrm{P}}$ : + present study; C Csepregi's results [5].

On the other hand, for our experimental results obtained by conductivity measurements, the activation energy of $V_{\mathrm{g}}$ stays constant for $0 \leqslant C_{\mathrm{P}} \leqslant 0.5 \%$ and then increases for $C_{\mathrm{P}}>0.5 \%$ (this will be investigated later).

In this method we assume that the final state observed on $R(t)\left(\lim _{t \rightarrow \infty} R(t)=R_{x}\right)$ for isothermal runs at each annealing $T$, and particularly at $560^{\circ} \mathrm{C}$, is a crystalline state. This has been verified by Reilly and Spear [6], who observe crystallization of such a doped material at a temperature as low as $510^{\circ} \mathrm{C}$, by characterizing and identifying the final state by using electronic transport measurements.

On the other hand, adopting this assmption we have been able to determine :

- the growth rate $V_{\mathrm{g}}$ as well as the nucleation rate $n$ for evaporated amorphous $\mathrm{Ge}$; these results are in excellent agreement with Barna et al. [11] whose results were obtained by using electron microscopy,

- $V_{\mathrm{g}}$ for evaporated amorphous $\mathrm{Si}$ in agreement with the results of Mayer $e t$ al. [12] by using channeling measurements.

In conclusion, it appears from this study that for doping levels $C_{\mathrm{P}} \leqslant 0.5 \%$, we observe a similar behaviour of $V_{\mathrm{g}}$ for two different kinds of amorphous silicon film obtained in different ways : one prepared by glow discharge decomposition of silane, and other obtained by the implantation method. 


\section{References}

[1] Christian, J. W., Phase Transformation Physical Metallurgy Ed. R. W. Cahn (North Holland, HY) 1970, Chap. X.

[2] Germain, P., Squelard, S., Bourgoin, J. and Gheorghiu, A., J. Appl. Phys. 48 (1977) 5.

[3] Germain, P., Zellama, K., Squelard, S., Bourgoin, J. and GheorghiU, A., J. Appl. Phys. 50 (1979) 6986.

[4] Zellama, K., Germain, P., Souelard, S., Bourgoin, J. and GheorghiU, A., J. Appl. Phys. 50 (1979) 6995.

[5] Csepregi, L., Kennedy, E. F., Gallagher, T. J., Mayer, J. W. and Sigmon, T. W., J. Appl. Phys. 48 (1977) 4234.

[6] Reilly, O. I. and Spear, W. E., Phil. Mag. B, 38 (1978) 295.

[7] Bourdon, B., Rapport de recherche (1977) Compagnie Générale d'Electricité.
[8] Zellama, K., Germain, P., Squelard, S., Bourdon, B., Fontenille, J. and Danielou, R., Phys. Rev. B. 23 (1981) 6648.

[9] Zellama, K., Thèse de Doctorat d'Etat, Université Paris 7 (1981) (unpublished).

[10] Germain, P. and Zellama, K. (in press), Thin solid films.

[11] Barna, A., Barna, P. B. and Pocza, J. F., J. Non-Cryst. Solids 8 (1972) 36.

[12] Mayer, J. W., Thin Films, Preparation and Properties : Chap. «Epitaxial Growth-Thermal, laser and electron beam induced " (Edited by K. N. Tu and R. Rosenberg), 1981, Pasadena, California. 